\title{
Proteomic Analysis of Human Serum for Finding Pathogenic Factors and Potential Biomarkers in Preeclampsia
}

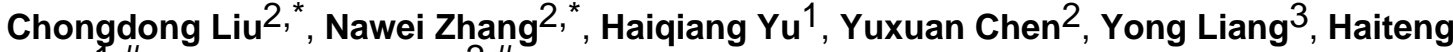 \\ Deng $^{1, \# \text {, and Zhenyu Zhang }}{ }^{2, \#}$ \\ ${ }^{1}$ The Rockefeller University, New York, NY 10065, USA \\ ${ }^{2}$ Beijing Chaoyang Hospital affiliated Capital Medical University, Beijing China \\ ${ }^{3}$ Taizhou Municipal Hospital affiliated Medical College of Taizhou University, Taizhou, China
}

\begin{abstract}
Objective(s)-To apply a novel proteomic method to discover potential pathogenic factors and biomarkers of preeclampsia.

Study design-Sera from five patients complicated with preeclampsia and five healthy pregnant controls were separately pooled. Each pool was treated with peptide ligand library beads (PLLBs) to remove high abundance proteins by affinity and thus enrich low abundance proteins. The proteins from the eluate were analyzed by a combination of 1D-Gel-LC-MS/MS. Protein expression levels were quantified using spectral counts and the extracted ion current.
\end{abstract}

Results-1172 unique proteins in preeclampsia and 1149 in healthy controls were identified in the present study. 51 proteins were differentially expressed between preeclampsia and healthy pregnant women including chorionic somatommammptropin hormone (CSH) and fibulin-1. 31 proteins identified were up-regulated and 20 were down-regulated.

Conclusions-The results demonstrate that peptide ligand library combining with 1D gel-LCMS/MS analysis is an efficient method to identify differentially expressed proteins in sera and two biological processes of complement and coagulation activations and lipid metabolism were involved in the pathogenesis of preeclampsia.

\section{Keywords}

preeclampsia; PLLB; biomarker; complement and coagulation; chorionic somatommammptropin hormone

\section{Introduction}

Preeclampsia is a pregnancy-specific syndrome characterized by hypertension and proteinuria. It occurs in $3-5 \%$ pregnancies and leads to high maternal and fetal morbidity

\footnotetext{
(C) 2010 Elsevier Ltd. All rights reserved.

\#Corresponding authors: 'Zhenyu Zhang, M.D., Ph.D., No8 Baijiazhuang Rd, Chaoyang District, Beijing 100020, China. zhenyuzhang2000@yahoo.com. Haiteng Deng, Ph.D., 1230 York Ave, Proteomic Resource Center of Rockefeller University, New York, NY 10065, USA. dengh@mail.rockefeller.edu.

*The first two authors contributed equally to the investigation.

Publisher's Disclaimer: This is a PDF file of an unedited manuscript that has been accepted for publication. As a service to our customers we are providing this early version of the manuscript. The manuscript will undergo copyediting, typesetting, and review of the resulting proof before it is published in its final citable form. Please note that during the production process errors may be discovered which could affect the content, and all legal disclaimers that apply to the journal pertain.
} 
and mortality [1]. Currently there are no predictive tests available for diagnosis of preeclampsia. Over the last two decades, researches have revealed that preeclampsia is a multi-systemic syndrome with complex pathophysiological changes, such as endothelial dysfunction, inflammatory response, activation of coagulation system and metabolic changes [2]. It is widely believed that the pathophysiological changes of preeclampsia may result from the abnormal expression of some proteins. Identification of these proteins could be of great help in elucidating the molecular basis of the pathogenesis as well as in serving as biomarkers for early diagnosis of the disease. Application of proteomic technologies has evolved as a major tool for biomarker discovery [3]. Proteins derived from biological fluids that can be accessed noninvasively are ideal candidate biomarkers. One challenge to identify these biomarkers is that 85 percent of the human serum proteins by mass are comprised of six high abundance proteins including albumin, subtypes $\mathrm{G}$ and $\mathrm{A}$ of immunoglobulin, transferrin, haptoglobin, and $\alpha-1$-antitrypsin. These components may mask the mass spectra of the interesting low abundance proteins. Methods have been developed to deplete the high abundance proteins derived from serum/plasma, such as immunodepletion, organic precipitation, affinity purification and solid phase extraction $[4,5]$.

Potential serum biomarkers of preeclampsia have been identified using proteomic methods. Our previous study of preeclampsia using surface-enhanced laser desorption lionization-time of flight-mass spectrometry (SELDI-TOF-MS) detected 10 significantly different protein peaks between hypertensive disorder complicating pregnancy and healthy controls [6]. A recent study using a combination of immuno-depletion and 2D DIGE has identified 39 differentially expressed proteins involved in lipid metabolism, coagulation, complement regulation, extracellular matrix remodeling, protease inhibitor activity and acute-phase responses, providing a comprehensive view of the synergism between pathways involved in the pathogenesis of preeclampsia [7]. The 2D gel electrophoresis approach is limited in sensitivity and can be inefficient when analyzing hydrophobic proteins or those with very high or low molecular weight. It is also known that other proteins are concomitantly removed during immuno-depletion process due to non-specific binding to the depleted proteins. On the other hand, the combination of 1D-Gel electrophoresis and LC-MS/MS has become a powerful approach owing to facile separation of proteins on 1D SDS PAGE followed by the powerful shotgun proteomic approach. An alternative approach, based on peptide-ligand-library affinity chromatography and 1D-Gel-LC-MS/MS has been used in the present study for identification of pathogenic factors in preeclampsia. Peptide ligand library affinity chromatography is a novel method for capturing and identifying the low abundance proteins [8]. In this method, a solid-phase combinatorial library of hexapeptides is coupled, via a shorter spacer, on poly (hydroxymethecrylate) beads, by a modified Merrifield approach. The hexapeptide ligands are synthesized from natural amino acid so the library contains millions of linear hexapeptide that are able to interact with a very large number of proteins present in a complex proteome. Lau Sennels et al [9] have reported a large scale proteomic study of human serum using peptide library beads and mass spectrometry. Analysis of the eluates from this combinatorial library resulted in the identification of 1559 proteins including a large number of low abundance proteins.

In the present work, we have applied the peptide ligand library beads (PLLBs)-based affinity method to the differential analysis of severe preeclampsia serum samples versus serum samples of healthy pregnant women. We have found that 51 proteins are differentially expressed between serum samples from healthy controls and severe preeclampsia patients. 


\section{Materials and methods}

\subsection{Subjects and sample collection}

Blood samples were taken from 5 pregnant women with severe preeclampsia and 5 healthy, gestational age-matched pregnant women. The diagnosis of preeclampsia was based on the criteria of the National High Blood Pressure Education Program working group on High Blood pressure in pregnancy. Severe preeclampsia was defined as increased blood pressure ( $\geq 160 \mathrm{mmHg}$ systolic or $\geq 110 \mathrm{mmHg}$ diastolic on $\geq 2$ occasions at least $6 \mathrm{~h}$ apart) that occurred after 20 weeks of gestation in women with preciously normal blood pressure, accompanied with proteinuria $(\geq 5 \mathrm{~g} / 24 \mathrm{~h})$ or proteinuria of $2^{+}$or more by dipstick measurement. No subject had a history of hypertension or renal diseases. Gestational agematched control subjects were apparently healthy and without hypertension or proteinuria. None of the control subjects suffered preeclampsia before. All samples were collected from the Obstetrics and Gynecology Department; Beijing Chaoyang Hospital affiliated Capital Medical University. The research protocol was approved by the Ethics Committee of Beijing Chaoyang Hospital. Serum samples were obtained from the peripheral blood by centrifuging at $4000 \mathrm{rpm}$ for 10 minutes at $4^{\circ} \mathrm{C}$ within 2 hours of the collection and stored at $-80^{\circ} \mathrm{C}$ until analyzed.

\subsection{Sample preparation}

Serum samples from 5 patients with severe preeclampsia and 5 healthy controls were pooled together, respectively. $300 \mu \mathrm{L}$ of the pooled serum samples was centrifuged to eliminate particles in suspension. $8 \mathrm{mg}$ of the PLLB resin (Peptide International, Lexington, KY) was suspended in $100 \mu \mathrm{L}$ of $50 \%$ methanol for 10 minutes and was washed three times with PBS solution ( $\mathrm{pH}=7.4)$. Note: the peptide ligand library beads are currently the product of BioRad Laboratories, Inc. (Hercules, CA) under the trade name of ProteoMiner. Then the pooled serum samples were incubated with the PLLB resin at room temperature $\left(22-25^{\circ} \mathrm{C}\right)$ on a soft shaker for 2 hours. After removing the unbound fraction, the PLLB resin was washed three times with PBS solution again. Proteins were eluted from the beads by incubating with LDS sample buffer (Invitrogen, Grand Island, NY) at $100^{\circ} \mathrm{C}$ for 5 minutes.

\subsection{Protein separation, in-gel digestion and LC-MS/MS analysis}

Proteins were separated on a 4-12\% gradient Tris-Glycine SDS-gel (Invitrogen, Grand Island, NY), and were stained with colloidal Coomassie Blue (Invitrogen, Grand Island, NY). Each lane was cut into 15 slices and each gel slice was reduced with $10 \mathrm{mM}$ dithiothreitol (Calbiochem, San. Diego, CA) and alkylated with $100 \mathrm{mM}$ iodoacetamide (Sigma, St Louis, MO). Then in gel digestion was carried out with the sequence grade modified trypsin (Promega, Fitchburg, WI) in $50 \mathrm{mM}$ ammonium bicarbonate at $37^{\circ} \mathrm{C}$ overnight. The peptides were extracted twice with $1 \%$ trifluoroacetic acid in $50 \%$ acetonitrile aqueous solution for 30 minutes.

For LC-MS/MS analysis, each digestion product was separated by a 60 min gradient elution at a flow rate $0.250 \mu \mathrm{L} / \mathrm{min}$ with the Dionex 3000 nano-HPLC system, which is directly interfaced with the Thermo LTQ-Orbitrap mass spectrometer. The analytical column was a home-made fused silica capillary column (75 $\mu \mathrm{m}$ ID, $150 \mathrm{~mm}$ length; Upchurch, Oak Harbor, WA) packed with C-18 resin (300 A, $5 \mu \mathrm{m}$, Varian, Lexington, MA). Mobile phase A consisted of $0.1 \%$ formic acid, and mobile phase B consisted of $100 \%$ acetonitrile and $0.1 \%$ formic acid. The LTQ-Orbitrap mass spectrometer was operated in the data-dependent acquisition mode using the Xcalibur 2.0.7 software and there is a single full-scan mass spectrum in the Orbitrap (400-1800 m/z, 30,000 resolution) followed by 6 data-dependent MS/MS scans in the ion trap at 35\% normalized collision energy. 


\subsection{Data processing and quantitative analysis}

The MS/MS spectra from each LC-MS/MS run were converted from RAW file format to DTA files using BioWorks 3.3.1 (Thermo-Fisher, San Jose, CA). The DTA files were searched against the human IPI database using an in-house Mascot searching algorithm. The following search parameters were used in all of the Mascot searches: maximum of 1 missed trypsin cleavages, cysteine carbamidomethyltion as fixed modification, methionine oxidation as the variable modification. The maximum error tolerance was $10 \mathrm{ppm}$ for MS and 1.2 Da for MS/MS. Proteins were designated as "hits" only when the Mascot score was more than 30 and there were at least 2 unique peptides matches. When several proteins matched the same sets of peptides, only the proteins with the greater percentage of coverage was selected.

Quantitation of protein expressions by spectral counts for each identified proteins was carried out using an in-house developed Perl script. Significance was regarded only when the ratio of spectral counts between two groups were more than 2 or less than 0.5. Extracted ion currents for selected peptides were also used to quantify the protein concentrations from different samples. Confirmation of some of the differentially expressed proteins in the present study was also carried out with isotope-encoded peptides corresponding to the tryptic peptides of the selected proteins. The same amount of pooled serum samples from severe preeclampsia and healthy controls were treated with PLLB resin, respectively, using the same protocol described above. The eluted proteins were separated on 1D SDS PAGE followed by in gel digestion. Then the tryptic peptides from each gel band were pooled and spiked with the isotope-encoded synthetic peptides as the internal standards followed by LCMS/MS analysis with LTQ-Orbitrap mass spectrometer.

\subsection{Western blot analysis}

$60 \mu \mathrm{g}$ serum proteins from 4 patients with severe preeclampsia and 4 healthy controls in the third trimester were separated respectively in NuPAGE Novex 4-12\% Bis Tris gradient gels (Invitrogen, Grand Island, NY) and transferred to a nitrocellulose membranes (Millipore, Billerica, MA) for 30 minutes using $1 \times$ NuPAGE transfer buffer. The membranes were blocked overnight at $4{ }^{\circ} \mathrm{C}$ in blocking buffer (5\% skim milk, $0.1 \%$ Tween $20,0.01 \mathrm{M}$ TBS) and incubated with primary antibodies in the blocking buffer for $120 \mathrm{~min}$ at room temperature. Antibodies specific to Transthyretin (TTR), Retinol-binding protein 4 (RBP4), CSH and Alpha-2-HS-glycoprotein (AHSG) (Abcam, Cambridge, MA) were used, respectively. After washes with TBST buffer ( $0.1 \%$ Tween $20,0.01 \mathrm{M}$ TBS), the membrane was incubated with secondary antibodies (goat antimouse/HRP conjugate) (Santa Cruz, Paso Robles, CA) for TTR, RBP, CSH and AHSG and detected with the Pierce chemiluminescent (ECL) kit (Thermo, Waltham, MA). Levels of proteins were then quantified by Image Quant TL Activation Wizard software.

\section{Results}

\subsection{Subject characteristics}

5 pregnant women complicated with preeclampsia and 5 healthy pregnant women were recruited in this study. They all underwent cesarean section in their third trimester to end the pregnancy. The characteristics of these pregnant women were listed in Table 1.

\subsection{PLLB-based Serum Sample Preparation}

As shown in Figure 1, a similar pattern of bands are detected for $2 \mu \mathrm{L}$ of pooled serum in lane 5 and 6 and $2 \mu \mathrm{L}$ of unbound material after incubation in lane 3 and 4, indicating that the relative concentration of the most abundant proteins does not change appreciably after saturation of their available ligands. The presence of a continuum of bands covering the 
entire molecular weight interval from 10-200 kDa in the two eluates from PLLBs are shown in lane 1 and 2, indicating the enrichment of low abundance proteins and the drastically reduced levels of the most abundant proteins present in the serum such as albumin at about $67 \mathrm{kDa}$.

\subsection{Identification of proteins by 1D Gel-LC-MS/MS}

After in-gel digestion, the tryptic peptides from each gel band were analyzed by LC-MS/ MS. 1172 proteins were identified from samples of preeclampsia patients and 1149 in normal pregnant women. The false positive rate for proteins identified with Mascot, as calculated by the decoy database search, was estimated to be $2 \%$. Although the numbers of proteins identified are not as high as what have been reported, these results are more reliable since the MS measurement was carried out with LTQ-Orbitrap mass spectrometer with the mass measurement error less than $10 \mathrm{ppm}$. The studies carried out with LTQ usually use a 3 $\mathrm{Da}$ as mass measurement error, which greatly increases the false positive rate.

Using PLLB treatment, we have been able to identify some low abundance proteins and proteins that were seldom implicated to preeclampsia, such as chorionic somatomammotropin hormone, a low abundance protein whose concentration in plasma was reported to be about 5-45 ng/mL [10]. An extracellular matrix protein, fibulin-1, was also identified. The MS/MS spectrum of a selected tryptic peptide of CSH and fibulin-1 is displayed in Figure 2A and Figure 2B, respectively, in which all major fragment ions match the $\mathrm{b}$ and $\mathrm{y}$ ions of the peptides from these two proteins.

\subsection{Identification of serum proteins differentially expressed in severe preeclampsia and healthy Controls}

When comparing Lane 1 from severe preeclampsia patients to Lane 2 from healthy pregnant women, staining intensities show significant differences in several gel bands, as shown in Figure-1. Spectral counts were used to quantify the expression levels of proteins in the selected gel bands as well as the whole lane, which use the number of spectra that have been assigned to a specific protein, to quantify the relative abundance of a protein from two samples and have been widely applied to biological systems. Using 2 fold or more changes as a determinant, we have identified 31 proteins up-regulated and 20 down-regulated in patients with preeclampsia comparing with healthy pregnant women, as displayed in Table 2. Manually confirmation of all the differentially expressed proteins was carried out with the extracted ion current of selected peptides. The intensity profiles of a peptide from $\mathrm{CSH}$ are displayed in Figure 3, suggesting that the concentration of CSH from preeclampsia patients is 7 times higher than that from healthy controls. Apolipoprotein E (ApoE) eluted from PLLBs was found to be up-regulated in preeclampsia using spectral counts and the extracted ion current. To further determine the concentration of ApoE, an isotope-encoded peptide corresponding to a tryptic peptide of ApoE was synthesized and used as an internal standard to quantify the concentration of ApoE in the PLLB-treated serum samples. The mass spectrum of the selected tryptic peptides versus the synthetic peptide is shown in Figure 4. The concentration of serum ApoE in patients with preeclampsia was determined as 198.42 $\mathrm{mg} / \mathrm{L}$ and $93.77 \mathrm{mg} / \mathrm{L}$ in healthy controls, respectively, which was consistent with results obtained by spectral count and extracted ion current.

\subsection{Validation of proteomic results by western blot analysis}

Four of the differentially expressed serum proteins (TTR, RBP4, CSH and AHSG) were analyzed by western blot, as shown in Figure 6 . The immunoblot analysis showed decreased TTR in the serum of severe preeclampsia patients with a mean band intensity of 2625.30 \pm 562.19 SD (mean optical density units) versus controls (17177.83 \pm 5608.32 ), $p<0.01$ (student's $t$-test, two tailed). This indicates that the concentration of TTR in control 
is 6 times higher than that in the serum of patients, in agreement with the result from spectra counts. Similarly, the concentration of RBP4 is two times lower in severe preeclampsia (30978.65 $\pm 15416.88 \mathrm{SD})$ than that in controls (71988.55 $\pm 18462.04 \mathrm{SD}), p<0.01$. In contrast, the analysis showed increased levels of CSH and AHSG (CSH: 18430.67 \pm 3986.95 SD in PE and 4841.45 \pm 3090.66 SD in control, $p<0.01$; AHSG: 27888.58+7585.27 SD in PE and $8626.815+3477.34 \mathrm{SD}$ in control, $p<0.01$ ). The relative abundance profiles, as determined by western blot analysis, were therefore consistent with the quantitative spectral counts data obtained for these four proteins.

\subsection{Biological processes and molecular functions of proteins differentially expressed in preeclampsia and healthy controls}

All differentially expressed proteins were annotated and analyzed using DAVID Bioinformatics Resources to connect the proteins to biological processes and pathways (Figure 5). The analysis demonstrated that 17 of the proteins differentially expressed were linked to complement and coagulation response and 15 were acute-phase-response proteins. Six proteins were extracellular matrix proteins. The analysis also revealed 3 major clusters of molecular function: 7 proteins were endopeptidase inhibitors, 5 were calcium-ion-binding proteins (APCS, F10, FGG, FBLN1, and PLG) and 8 were heparin-binding proteins (ApoB, ApoH, FN1, KING1, PF4, SERPINC1, VTN and Hyaluronan-binding protein 2). Collectively, these observations implicate that acute phase, complement and coagulation response play a major role in preeclampsia.

\section{Discussion}

In the present study, a novel method of peptide ligand library affinity chromatography combining with $1 \mathrm{D}$ gel-LC-MS/MS analysis was employed to identify proteins differentially expressed in sera of preeclampsia patients comparing to those of healthy pregnant women. It has been documented that the PLLB is an efficient means to reduce high abundance proteins for the identification of low-abundance proteins and is highly reproducible. Analysis of serum samples treated with PLLB in triplicate resulted in the identical 1D SDS images in our experiments and in the literature [11-13]. Like other affinity-based depletion methods, PLLB is only to enrich a subproteome, which is based on the selective binding of proteins by hexapeptides. Proteins that don't bind to hexapeptides are not retained on the beads. Furthermore, the comparison can only be performed for the proteins that have not saturated their respective binding sites on the PLLBs. Since there are 6 proteins accounting for $85 \%$ of the bulk mass of the proteins in human serum, it's reasonable to assume that the other proteins do not fully occupy their binding sites and can be analyzed with the amount of beads according to the manufacturer's instruction. Using PLLB-treated serum sample 51 proteins were identified to be differentially expressed between severe preeclampsia women and healthy pregnant women in the third trimester based on the spectral counts.

Of the 51 proteins differently expressed in our series, ApoE, ApoA2, ApoL1, ApoH, CLU (ApoJ), SAA4 [14] were all apolipoproteins involved in lipid metabolism. ApoA2, ApoH and SAA4 were also linked to acute-phase response $[15,16]$. Other HDL associated proteins, SERPINF1, AHSG, TTR and RBP4, were also identified and differentially expressed between preeclampsia and normal pregnant women. With targeted LC-MS analysis, we determined the concentrations of ApoE in the pooled sera of preeclampsia and normal control pregnancies, as $198.42 \mathrm{mg} / \mathrm{L}$ and $93.77 \mathrm{mg} / \mathrm{L}$, respectively. ApoE expression in serum of patients was about 2 -fold higher than that of healthy pregnancies. The results demonstrate that lipid metabolism is closely involved in pathogenesis of preeclampsia and is consistent with the previously published results [17]. Changes of Pregnancy zone protein (PZP), APCS, fibrinogen, hyaluronan-binding protein, and inter-alpha (globulin) were identified and were consistent with the earlier report by Blumenstein et al [7]. In addition, 
we were able to identify some low abundance proteins such as $\mathrm{CSH}$, a plasma protein secreted by the syncytiotrophoblast of human placenta. And the maternal serum level of $\mathrm{CSH}$ elevates in relation to the growth of the fetus and placenta [18]. CSH reportedly has lipolytic activity and the adverse effect of free fatty acid in the preeclampic maternal circulation may be originated from the up-regulation of $\mathrm{CSH}$ [19]. In the present study, the expression of $\mathrm{CSH}$ was up-regulated in patients with preeclampsia and is in agreement with the earlier reports showing that hyperplasia of the cytotrophoblast accompanied by its differentiation into new syncytiotrophoblast tissue in preeclampsia [20]. More experimental measurements are being conducted to establish that CSH is a potential biomarker associated with the pathophysiology of preeclampsia.

Expression of fibulin-1 was found to be up-regulated in preeclampsia. Fibulin is a member of extracellular-matrix (ECM) protein family discovered a little more than a decade ago [21] and is less characterized, especially in the pathogenesis of preeclampsia. Fibulin-1 can colocalize with elastin in the core of mature elastin-containing fibres in blood vessels [22], elevated expression of which is induced in response to injury [23] and this fiber is associated with atherosclerosis to perform acute myocardial infarction [24,25]. In the present study, upregulation of fibronectin was found in the sera of pregnant women complicated with preeclampsia, which is recognized as a valuable biomarker for the assessment of endothelial damage in preeclampsia [26]. Up-regulation of fibulin-1 and fibronectin indicates atherogenesis of the arteriole, and ischemia and hypoxia occur in preeclampsia.

DAVID Bioinformatics Resources were used to connect the differentially expressed proteins to biological processes and pathways. We found that 28 of the proteins differentially expressed in preeclampsia were involved in acute phase, complement and coagulation responses. It has been suggested that preeclampsia is a disorder characterized by intravascular and endothelial cell dysfunction [27,28], related to pregnancy-induced autoimmune condition [29,30]. Abnormal activation of the immune system has been reported in preeclampsia [31-35]. A recent review has linked the inflammation relating to activation of the complement system with preeclampsia [36]. Although there are still controversies concerning the role of immunological mechanisms engaged in preeclampsia, our results showed the immune system involved in pathophysiology of preeclampsia.

However, some known factors associated with preeclampsia were not identified in the present study including soluble fms-like tyrosine kinase 1 (sFlt-1) and placental growth factor (PIGF) [37]. This is partly because different detection methods were used. Peptide library affinity purification is applicable to the serum proteins that have their respective binding ligands on the beads. The limitation is that proteins may not bind to hexapeptide beads with high affinity and they will not be captured and detected [38]. The other reason is that the detection limits of antibody-based methods are lower than that of mass spectrometry. Powers et al [39] detected the maternal serum concentrations of soluble Fmslike tyrosine kinase 1 across pregnancy in women who developed preeclampsia by immunosorbent assay. The concentration detected in the preeclampsia pregnancy was about $4.5 \mathrm{ng} / \mathrm{ml}$. That is below the detection limit of the mass spectrometry.

In the present study, we used spectral counts to identify differentially expressed proteins in serum from patients with preeclampsia and healthy controls. Spectral count is simple and sensible to protein abundance changes, which correlates well with protein abundance [40]. However, it may not give the true representation of differences of low abundance proteins or small proteins between two samples. Extracted ion current is an alternative approach to determine the differentially expressed proteins by using the sum of the ion signal for a particular mass to charge $(\mathrm{m} / \mathrm{z})$ value. In the present work, extracted ion current was used to confirm all the differentially expressed proteins listed in Table 2 including CSH that is a low 
abundance protein in sera. The addition of isotope-encoded peptide as the internal standards is an alternative approach to determine the absolute concentrations of targeted proteins. A synthetical isotope-encoded ApoE peptide was used in the present work to determine the concentrations of ApoE in preeclampsia and the health controls. It is worth noting that ApoE measured in the present work $(94 \mathrm{mg} / \mathrm{ml})$ should be a fraction of total ApoE that was bound to PLLBs. The concentrations of ApoE in serum were reported at $16-169 \mathrm{mg} / \mathrm{L}$ as determined by immunoturbidimetry [41]. The current measurement indicates that most ApoE proteins are retained by PLLBs.

In conclusion, the results demonstrate that peptide ligand library affinity chromatography combining with 1D gel-LC-MS/MS analysis is a useful method to identify proteins differently expressed in sera of pregnancies complicated with preeclampsia. The changes of protein expressions are mainly associated with acute phase, complement and coagulation response, concomitant with lipid metabolism and ECM remodeling. Chorionic somatomammotropin hormone is suggested to be a potential biomarker for diagnosis of preeclampsia.

\section{Acknowledgments}

The work was supported by the Sino-US Cooperation Funds 2007DFA301080 and by NIDCR/NIH Grant U19 DE018385. We thank Dr Chandramouli and Mr Fernandez for reviewing the manuscripts.

\section{References}

1. Laivuori H. Genetics aspects of preeclampsia. Front Biosci 2007;12:2372-2382. [PubMed: 17127247]

2. Roberts JM, Lain KY. Recent insights into the pathogenesis of pre-eclampsia. Placenta 2002;23:359-372. [PubMed: 12061851]

3. Petricoin EF, Liotta LA. Clinical application of proteomics. J Nutrition 2003;133:2476S-2484S. [PubMed: 12840227]

4. Hammond DJ, Lathrop JT. The discovery of trace therapeutic proteins from complex biological materials. Innovations in Pharm Tech 2005;17:38-41.

5. Fortis F, Guerrier L, Areces LB, Antonioli P, Hayes T, Carrick K, Hammond D, Boschetti E, Righetti PG. A new approach for the detection and identification of protein impurities using combinatorial solid-phase ligand libraries. J Proteome Res 2006;5:2577-2585. [PubMed: 17022629]

6. Gong LY, Zhang ZY, Zheng YH, Zhang JZ. Study of a serum protein fingerprint diagnostic model in patients with hypertensive disorder complicating pregnancy. Chin J Obstet Gynecol 2007;42:822-825.

7. Blumenstein M, McMaster MT, Black MA, Wu S, Prakash R, Cooney J, McCowan LM, Cooper GJ, North RA. A proteomic approach identifies early pregnancy biomarkers for preeclampsia: Novel linkages between a predisposition to preeclampsia and cardiovascular disease. Proteomics 2009;9:2929-2945. [PubMed: 19444803]

8. Thulasiraman V, Lin S, Gheorghiu L, Lathrop J, Lomas L, Hammond D, Boschetti E. Reduction of concentration difference of proteins from biological liquids using combinatorial ligands. Electrophoresis 2005;26:3561-3571. [PubMed: 16167368]

9. Sennels L, Salek M, Lomas L, Boschetti E, Righetti PG, Rappsilber J. Proteomics analysis of human blood serum using peptide library beads. J Proteome Res 2007;6:4055-4062. [PubMed: 17877382]

10. Natelson BH, Holaday J, Meyerhoff J, Stokes PE. Temporal changes in growth hormone, cortisol, and glucose: relation to light onset and behavior. Am 1975;229:409-415.

11. Li L, Sun CJ, Freeby S, Yee D, Jaquinod SK, Guerrier L, Boschetti E, Lomas L. Protein sample treatment with peptide ligand library: coverage and consistency. J Proteomics Bioinform 2009;2(12):485-494. 
12. Castagna A, Cecconi D, Sennels L, Rappsilber J, Guerrier L, Fortis F, Boschetti E, Lomas L, Righetti PG. Exploring the hidden human urinary proteome via ligand library beads. J Proteome Res 2005;4(6):1917-1930. [PubMed: 16335936]

13. Guerrier L, Claverol S, Fortis F, Rinalducci S, Timperio AM, Antonioli P, Jandrot-Perrus M, Boschetti E, Righetti PG. Exploring the platelet proteome via combinatorial, hexapeptide ligand libraries. J Proteome Res 2007;6(11):4290-4303. [PubMed: 17918985]

14. Beer MD, Yuan T, Kindy MS, Asztalos BF, Roheim PS, Beer FC. Characterization of constitutive human serum amyloid A protein (SAA4) as an apolipoprotein. J Lipid Res 1995;36:526-534. [PubMed: 7775864]

15. Vaisar T, Pennathur S, Green PS, Gharib SA, Hoofnagle AN, Cheung MC, Byun J, Vmicroliteretic S, Kassim S, Singh P, Chea H, Knopp RH, Brunzell J, Geary R, Chait A, Zhao XQ, Elkon K, Marcovina S, Ridker P, Oram JF, Heinecke JW. Shotgun proteomics implicates protease inhibition and complement activation in the antiinflammatory properties of HDL. J Clin Invest 2007;117:746-756. [PubMed: 17332893]

16. Schreiber BM, Veverbrants M, Fine RE, Blusztajn JK, Salmona M, Patel A, Sipe JD. Apolipoprotein serum amyloid A down-regulates smooth-muscle. Biochem J 1999;344(Pt 1):7-13. [PubMed: 10548527]

17. Potter JM, Nestel PJ. The hyperlipidemia of pregnancy in normal and complicated pregnancies. Am J Obstet Gynecol 1979;133:165-170. [PubMed: 217273]

18. Landek-Salgado MA, Gutenberg A, Lupi I, Kimura H, Mariotti S, Rose NR, Caturegli P. Pregnancy, postpartum autoimmune thyroiditis, and autoimmune hypophysitis: Intimate relationships. Autoimmun Rev. 2009 [Epub ahead of print].

19. Murai JT, Muzykanskiy E, Taylor RN. Maternal and fetal modulators of lipid metabolism correlate with the development of preeclampsia. Metabolism 1997;46(8):963-967. [PubMed: 9258283]

20. Crosignani, PG. Correlation of human chorionic somatomammotropin (hCS) with fetal nutrition. In: Josimovitch, JB., editor. Lactogenic Hormones, Fetal Nutrition and Lactation. New York: John Wiley; 1973. p. 203-220.

21. Argraves WS, Dickerson K, Burgess WH, Ruoslahti E. Fibulin, a novel protein that interacts with the fibronectin receptor $\beta$ subunit cytoplasmic domain. Cell 1989;58:623-629. [PubMed: 2527614]

22. Roark EF, Keene DR, Haudenschild CC, Godyna S, Little CD, Argraves WS. The association of human fibmicroliterin-1 with elastic fibers: an immunohistological, ultrastructural, and RNA study. J Histochem Cytochem 1995;43:401-411. [PubMed: 7534784]

23. Redfern CH, Degtyarev MY, Kwa AT, Salomonis N, Cotte N, Nanevicz T, Fidelman N, Desai K, Vranizan K, Lee EK, Coward P, Shah N, Warrington JA, Fishman GI, Bernstein D, Baker AJ, Conklin BR. Conditional expression of a Gi-coupled receptor causes ventricmicroliterar conduction delay and a lethal cardiomyopathy. Proc Natl Acad Sci USA 2000;97:4826-4831. [PubMed: 10781088]

24. Tran H, Tanaka A, Litvinovich SV, Medved LV, Haudenschild CC, Argraves WS. The interaction of fibulin-1 with fibrinogen. A potential role in hemostasis and thrombosis. J Biol Chem 1995;270:19458-19464. [PubMed: 7642629]

25. Kawata K, Tanaka A, Arai M, Argraves WS, Fukutake K. Alteration of plasma fibulin-1 concentrations in ischemic heart diseases. Jpn J Thromb Hemostasis 2001;12:126-132.

26. Shaarawy M, Didy HE. Thrombomodulin, plasminogen activator inhibitor type 1 (PAI-1) and fibronectin as biomarkers of endothelial damage in preeclampsia and eclampsia. Int J Gynaecol Obstet 1996;55(2):135-139. [PubMed: 8960994]

27. Roberts JM, Taylor RN, Musci TJ, Rodgers GM, Hubel CA, McLaughlin MK. Preeclampsia: an endothelial cell disorder. Am J Obstet Gynecol 1989;161:1200-1204. [PubMed: 2589440]

28. Dadelszen PV, Wilkins T, Redman CW. Maternal peripheral blood leukocytes in normal and preeclamptic pregnancies. Br J Obstet Gynaecol 1999;106:576-581. [PubMed: 10426616]

29. Xia Y, Kellems RE. Is preeclampsia an autoimmune disease? Clin Immunol 2009;133:1-12. [PubMed: 19501024]

30. Gleicher N. Why much of the pathophysiology of preeclampsia-eclampsia must be of an autoimmune nature. Am J Obstet Gynecol 2007;196:5.e1-5.e7. [PubMed: 17240219] 
31. Redman CW, Sacks GP, Sargent IL. Preeclampsia: an excessive maternal inflammatory response to pregnancy. Am J Obstet Gynecol 1999;180:499-506. [PubMed: 9988826]

32. Sacks GP, Studena K, Sargent K, Redman CW. Normal pregnancy and preeclampsia both produce inflammatory changes in peripheral blood leukocytes akin to those of sepsis. Am J Obstet Gynecol 1998;179:80-86. [PubMed: 9704769]

33. Gervasi MT, Chaiworapongsa T, Pacora P, Naccasha N, Yoon BH, Maymon E, Romero R. Phenotypic and metabolic characteristics of monocytes and granulocytes in preeclampsia. Am J Obstet Gynecol 2001;185:792-797. [PubMed: 11641653]

34. Chaouat G, Robillard PY, Dekker G. Fourth international workshop on immunology of preeclampsia, December 2004, Reunion, France. J Reprod Immunol 2005;67:103-111. [PubMed: 16315347]

35. Saito S, Sakai M. Th1/Th2 balance in preeclampsia. J Reprod Immunol 2003;59:161-173. [PubMed: 12896820]

36. Lynch AM, Salmon JE. Dysregulated complement activation as a common pathway of injury in preeclampsia and other pregnancy complications. Placenta 2010;31:1-7. [PubMed: 19917514]

37. Shokry M, Bedaiwy MA, Fathalla MM, Alsemary A, Elwakil S, Murphy A. Maternal serum placental growth factor and soluble fms-like tyrosine kinase 1 as early predictors of preeclampsia. Acta Obstet Gynecol Scand 2010;89(1):143-146. [PubMed: 20021269]

38. Guerrier L, Righetti PG, Boschetti E. Reduction of dynamic protein concentration range of biological extracts for the discovery of low-abundance proteins by means of hexapeptide ligand library. Nat Protoc 2008;3(5):883-890. [PubMed: 18451796]

39. Powers RW, Roberts JM, Cooper KM, Gallaher MJ, Frank MP, Harger GF, Ness RB. Maternal serum soluble fms-like tyrosine kinase 1 concentrations are not increased in early pregnancy and decrease more slowly postpartum in women who develop preeclampsia. Am J Obstet Gynecol 2005;193(1):185-191. [PubMed: 16021077]

40. Old WM, Meyer-Arendt K, Aveline-Wolf L, Pierce KG, Mendoza A, Sevinsky JR, Resing KA, Ahn NG. Comparison of label-free methods for quantifying human proteins by shotgun proteomics. Mol Cell Proteomics 2005;4(10):1487-1502. [PubMed: 15979981]

41. Vincent-Viry M, Schiele F, Gueguen R, Bohnet K, Visvikis S, Siest G. Biological variations and genetic reference value for apolipoprotein E serum concentrations: results from the STANISLAS cohort study. Clin Chem 1998;44(5):957-965. [PubMed: 9590368] 


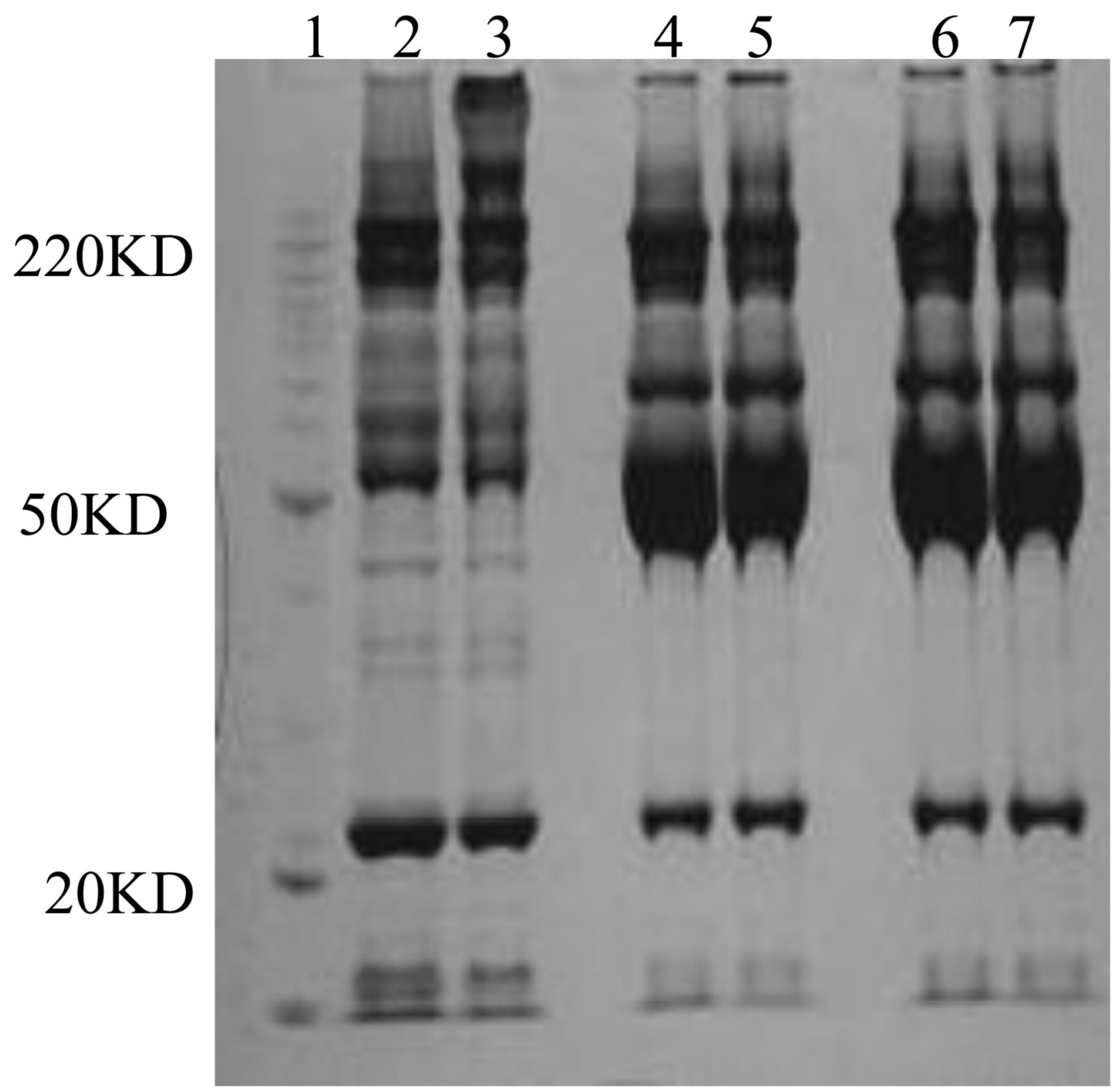

Figure 1.

1D-SDS-PAGE gel images of serum proteins before and after PLLB treatment. Lane 1: molecular weight marker. Lanes 2 and 3: serum proteins of healthy pregnant and preeclampsia eluted from the PLLB. Lane 4 and 5: proteins from $2 \mu \mathrm{L}$ of the unbound fraction; and Lanes 6 and 7: proteins from 2 microliter serum of healthy pregnant and preeclampsia patients, respectively. 

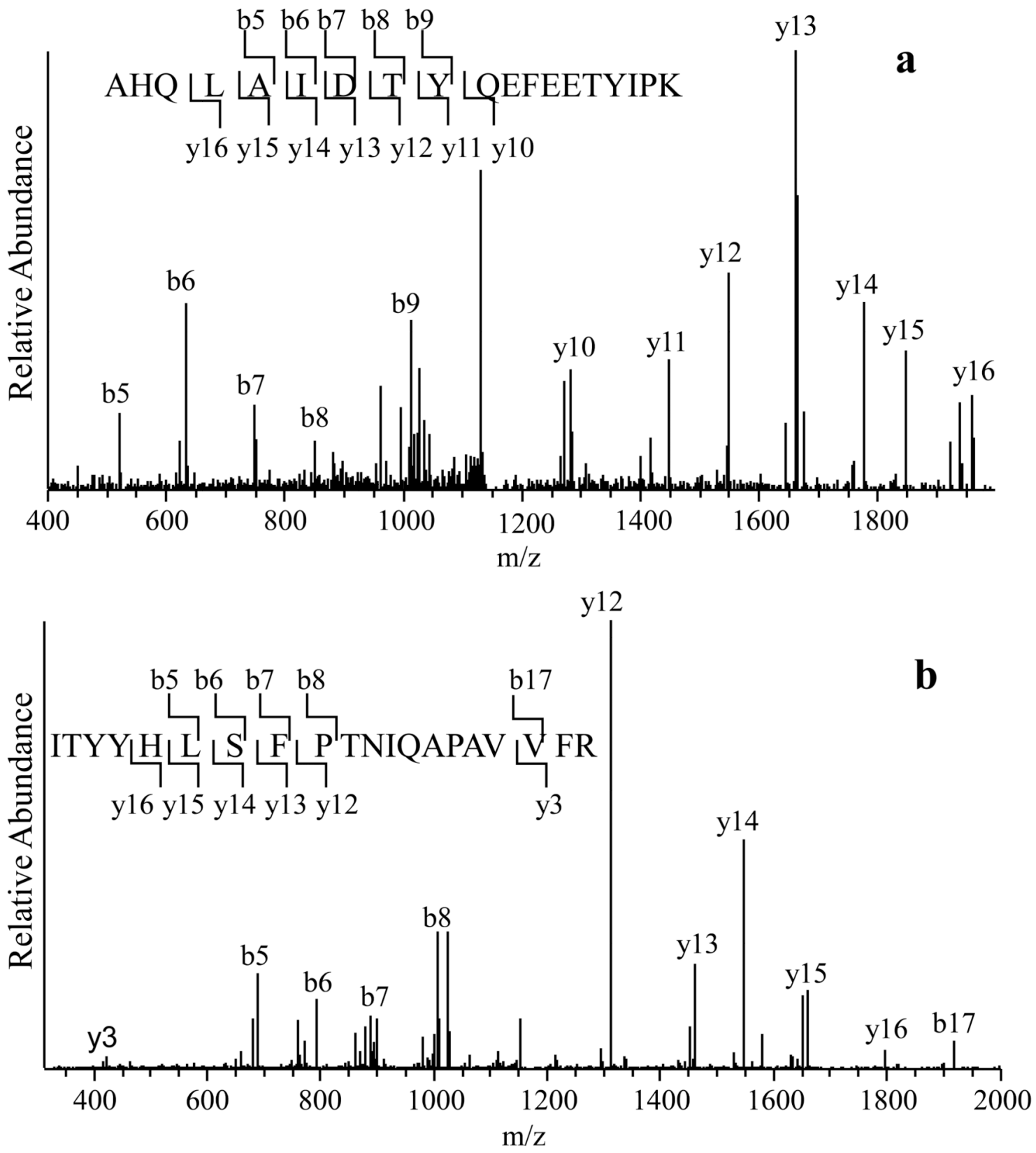

Figure 2.

(a). The MS/MS spectrum of a peptide ion (monoisotopic mass 2296.1343), the fragments of which matched to the peptide sequence AHQLAIDTYQEFEETYIPK from CSH 1.

(b). The MS/MS spectrum of a peptide ion (monoisotopic mass 2337.2619), the fragments of which matched to the sequence ITYYHLSFPTNIQAPAVVFR from Fibulin-1. 


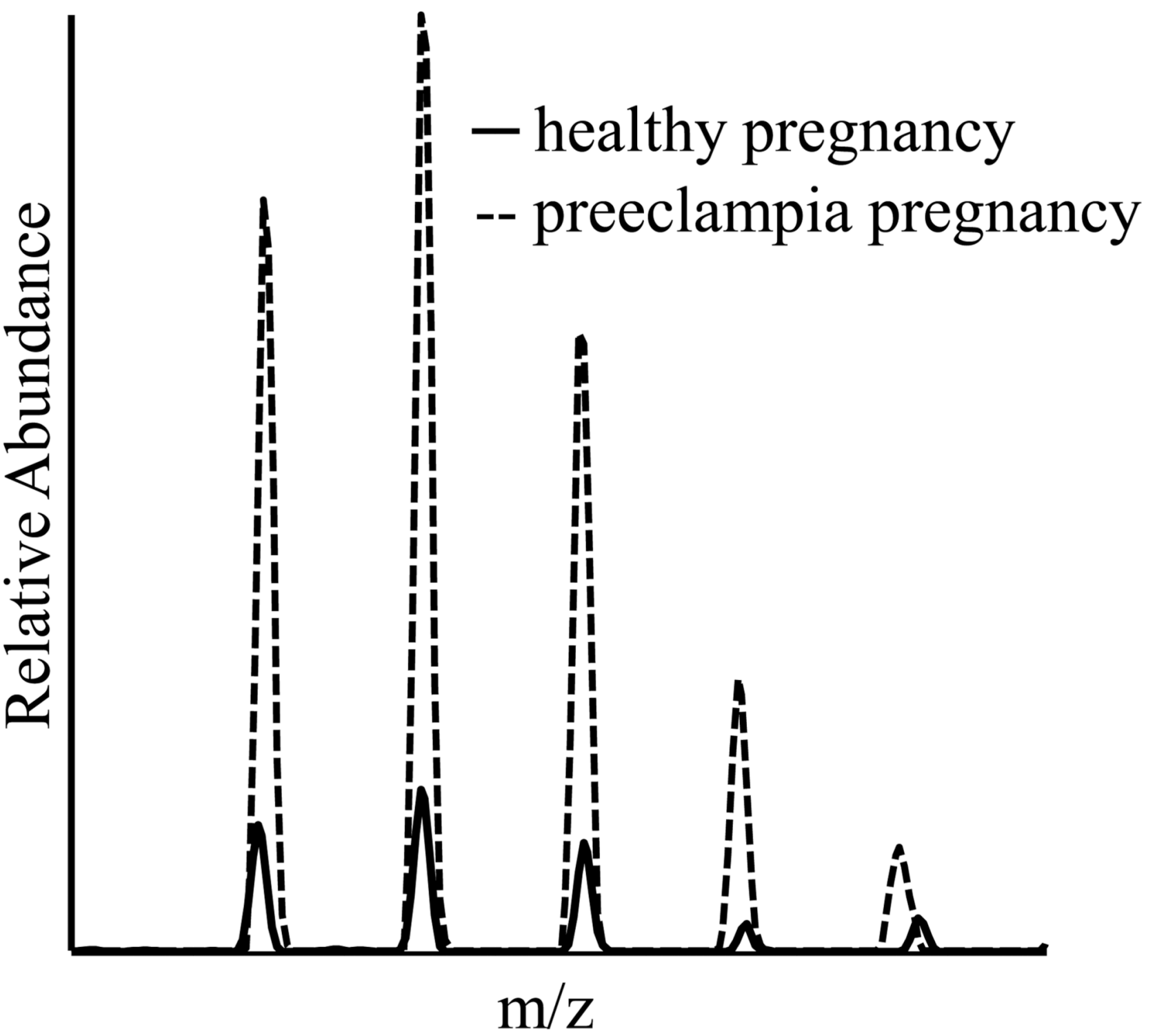

Figure 3.

The overlapped mass spectra of the peptide AHQLAIDTYQEFEETYIPK of CSH 1 from preeclampsia and healthy controls. The solid line represents the peptide ion from healthy controls and the dotted one represents the peptide ion from preeclampsia patients. The concentration of CSH 1 in serum of preeclampsia is 7 times higher than that of healthy pregnancy. 


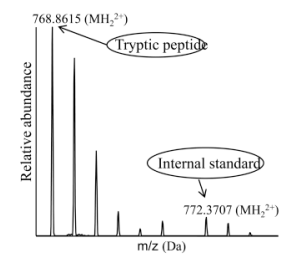

Figure 4.

The mass spectra of the tryptic peptide SWFEPLVEDMQR from ApoE and the corresponding isotope encoded counterpart. The intensity ratio of the two monoisotopic peaks was used to determine the concentrations of ApoE. 


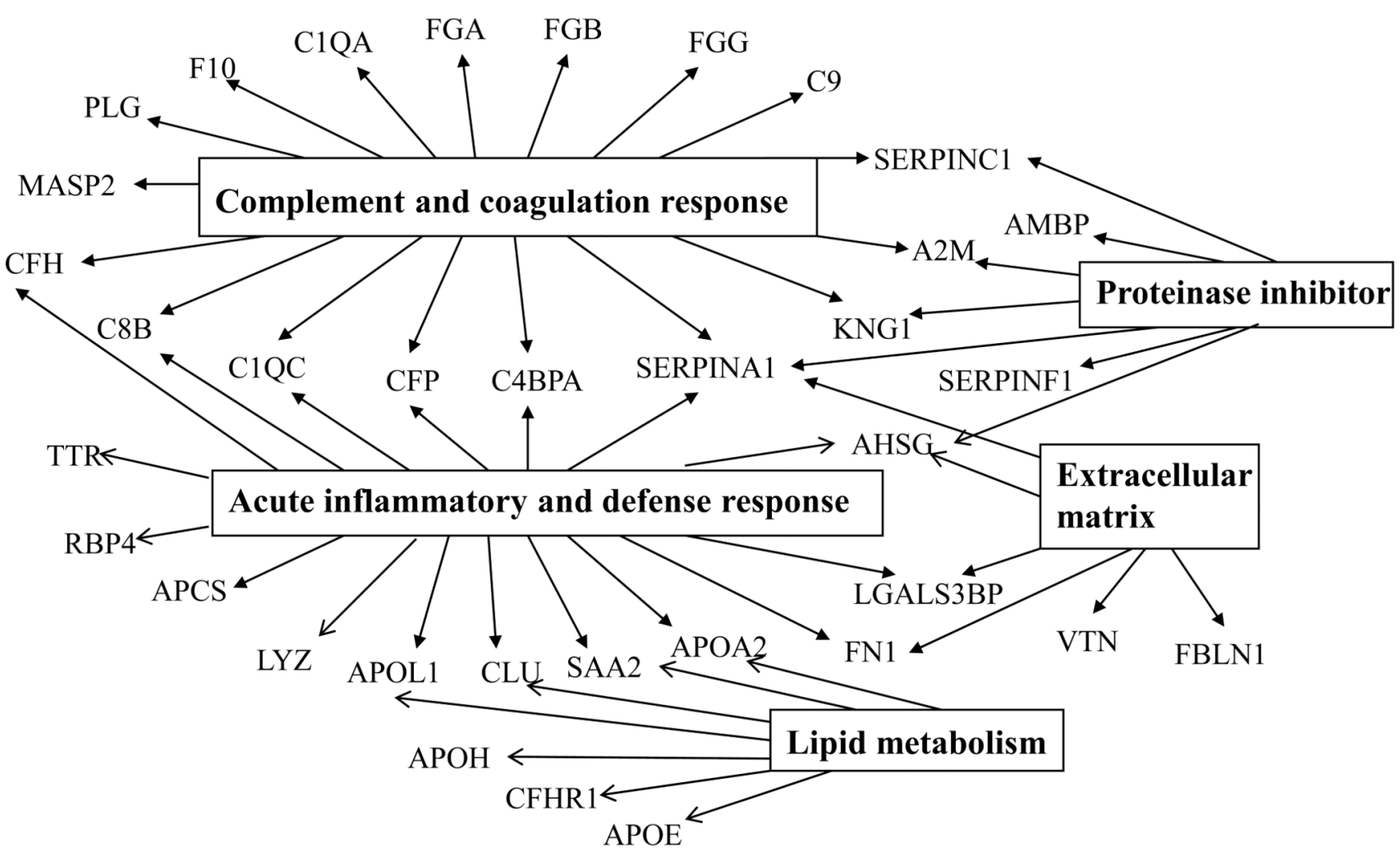

Figure 5.

Biological processes and molecular functions of proteins implicated to preeclampsia. All the differentially expressed proteins were analyzed using DAVID Bioinformatics Resources showing significant enrichment of proteins involved in complement and coagulation response, acute phase response, protease inhibitor activity, lipid metabolism and extracellular matrix remodeling. 


\section{Controls Preeclampsia}

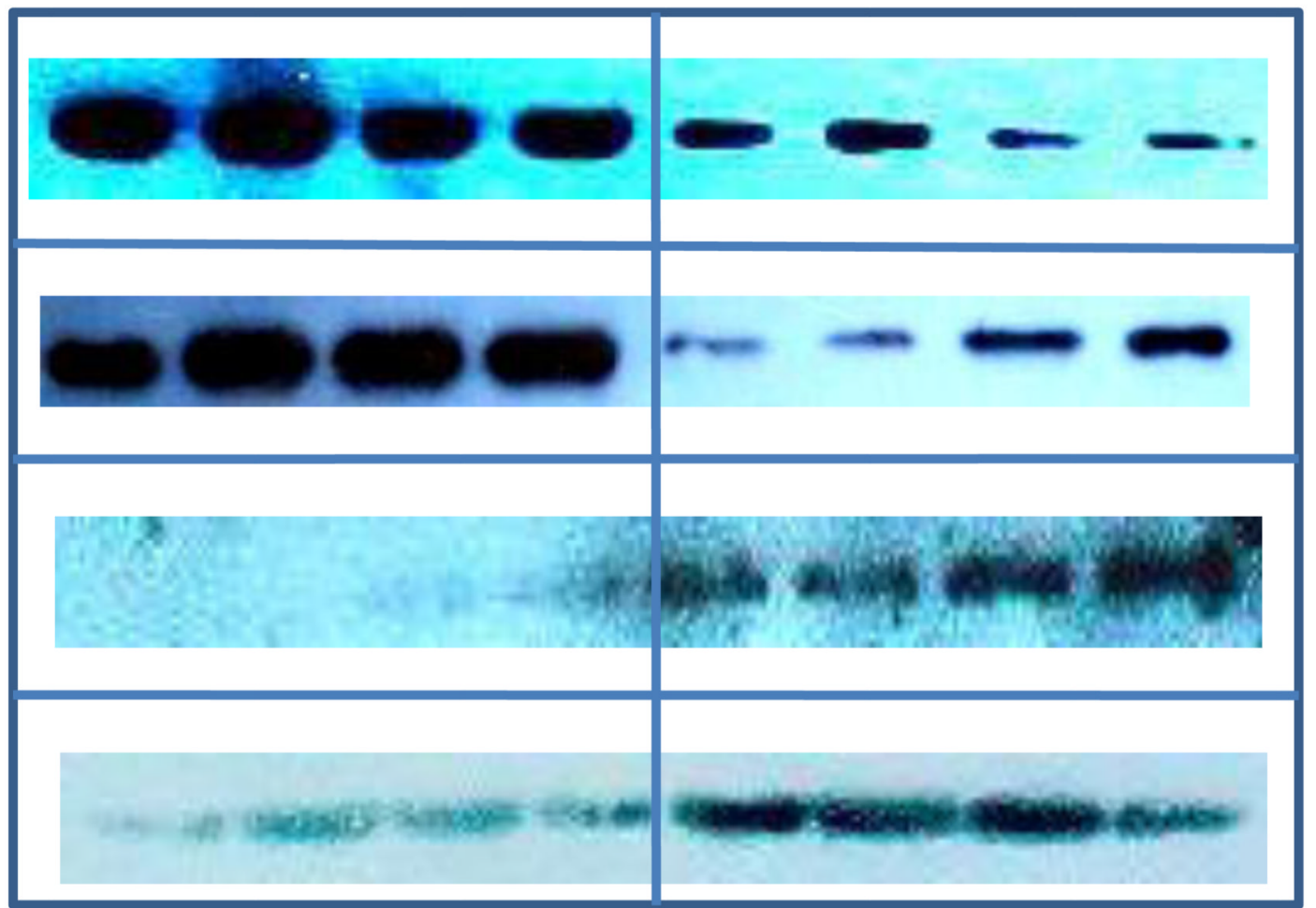

TTR

RBP4

$\mathrm{CSH}$

AHSG

Figure 6.

Western blot analysis of TTR, RBP4, CSH and AHSG, showing that expressions of TTR and RBP4 were down-regulated, while expressions of CSH and AHSG were up-regulated in patients with preeclampsia compared with those in healthy controls $(P<0.01)$. 


\section{Table 1}

Characteristics of all the study subjects

\begin{tabular}{ccc}
\hline & $\begin{array}{c}\text { Normal pregnant women } \\
(\mathbf{n = 5})\end{array}$ & $\begin{array}{c}\text { Preeclampic patients } \\
(\mathbf{n = 5})\end{array}$ \\
\hline Maternal age (y) & $28.2 \pm 1.8$ & $30.3 \pm 2.4$ \\
Gestational weeks (w) & $38.6 \pm 0.4$ & $36.4 \pm 1.2$ \\
SBP(mmHg) & $108.3 \pm 2.7$ & $166.2 \pm 5.7^{*}$ \\
DBP(mmHg) & $70.2 \pm 2.9$ & $107.3 \pm 7.5^{*}$ \\
\hline
\end{tabular}

The statistical analysis of characteristics of these pregnant women was performed with SPSS for windows 13.0 using one-way analysis of variance. Data are described as mean \pm standard. Significance is set as $P<0.05$.

${ }^{*}<<0.05$. 
Table 2

Serum proteins differentially expressed between patients with preeclampsia and healthy controls in the third trimester.

\begin{tabular}{|c|c|}
\hline Protein ID & Protein Name \\
\hline \multicolumn{2}{|l|}{ Up-regulated } \\
\hline IPI00553177 & Serpin peptidase inhibitor, clade A, member 1 \\
\hline IPI00022431 & Alpha-2-HS-glycoprotein \\
\hline IPI00022426 & AMBP protein \\
\hline IPI00021842 & Apolipoprotein E \\
\hline IPI00298828 & Apolipoprotein $\mathrm{H}$ \\
\hline IPI00017601 & Ceruloplasmin \\
\hline IPI00000891 & Chorionic somatomammotropin hormone \\
\hline IPI00291262 & Clusterin \\
\hline IPI00019576 & Coagulation factor $\mathrm{X}$ \\
\hline IPI00022392 & Complement $\mathrm{C} 1 \mathrm{q}$ subcomponent subunit A \\
\hline IPI00022394 & Complement $\mathrm{C} 1 \mathrm{q}$ subcomponent subunit $\mathrm{C}$ \\
\hline IPI00294395 & Complement component $\mathrm{C} 8$ beta chain \\
\hline IPI00022395 & Complement component C9 \\
\hline IPI00029739 & Complement factor $\mathrm{H}$ \\
\hline IPI00167093 & Complement factor H-related 1 \\
\hline IPI00021364 & Complement factor properdin \\
\hline IPI00021885 & Fibrinogen alpha chain \\
\hline IPI00298497 & Fibrinogen beta chain \\
\hline IPI00021891 & Fibrinogen gamma chain \\
\hline IPI00022418 & Fibronectin \\
\hline IPI00296537 & Fibulin-1 \\
\hline IPI00023673 & Galectin-3-binding protein \\
\hline IPI00746623 & Hyaluronan-binding protein 2 \\
\hline IPI00215894 & Kininogen-1 \\
\hline IPI00019038 & Lysozyme C \\
\hline IPI00006114 & Serpin peptidase inhibitor, clade $\mathrm{F}$, member 1 \\
\hline IPI00019580 & Plasminogen \\
\hline IPI00002903 & Pregnancy-specific beta-1-glycoprotein 3 \\
\hline IPI00477046 & Pregnancy-specific beta-1-glycoprotein 4 \\
\hline IPI00555812 & Vitamin D-binding protein \\
\hline IPI00298971 & Vitronectin \\
\hline \multicolumn{2}{|c|}{ Down-regulated } \\
\hline IPI00478003 & Alpha-2-macroglobulin \\
\hline IPI00008554 & Angiogenin \\
\hline IPI00032179 & Serpin peptidase inhibitor, clade $\mathrm{C}$, member 1 \\
\hline IPI00021854 & Apolipoprotein A-II \\
\hline IPI00022229 & Apolipoprotein B-100 \\
\hline
\end{tabular}




\begin{tabular}{ll}
\hline Protein ID & Protein Name \\
\hline IPI00186903 & Apolipoprotein-L1 \\
IPI00021727 & C4b-binding protein alpha chain \\
IPI00011264 & Complement factor H-related protein 1 \\
IPI00026199 & Glutathione peroxidase 3 \\
IPI00410714 & Hemoglobin subunit alpha \\
IPI00217473 & Hemoglobin subunit zeta \\
IPI00180190 & Leucine-rich repeat-containing protein 6 \\
IPI00294713 & Mannan-binding lectin serine protease 2 \\
IPI00022420 & Plasma retinol-binding protein 4 \\
IPI00022446 & Platelet factor 4 \\
IPI00025426 & Pregnancy zone protein \\
IPI00006146 & Serum amyloid A2 protein \\
IPI00019399 & Serum amyloid A-4 protein \\
IPI00022391 & Serum amyloid P-component \\
IPI00022432 & Transthyretin \\
\hline
\end{tabular}

